\title{
Treatment outcomes and their determinants in HIV patients on Anti-retroviral Treatment Program in selected health facilities of Kembata and Hadiya zones, Southern Nations, Nationalities and Peoples Region, Ethiopia
}

\author{
Wondimu Ayele $^{1 *}$, Afework Mulugeta ${ }^{2}$, Alem Desta $^{2}$ and Felicia A. Rabito ${ }^{3}$
}

\begin{abstract}
Background: Ethiopia has been providing free Antiretroviral Treatment (ART) since 2005 for HIV/AIDS patients. ART improves survival time and quality of life of HIV patients but ART treatment outcomes might be affected by several factors. However, factors affecting treatment outcomes are poorly understood in Ethiopia. Hence, this study assesses treatment outcomes and its determinants for HIV patients on ART in selected health facilities of Kembata and Hadiya zones.

Methods: A retrospective cohort study was conducted on 730 adult HIV/AIDS patients who enrolled antiretroviral therapy from 2007 to 2011 in four selected health facilities of Kembata and Hadiya zones of Southern Ethiopia. Study subjects were sampled from the health facilities based on population proportion to size. Data was abstracted using data extraction format from medical records. Kaplan-Meier survival function was used to estimate survival probability. Cox proportional hazards regression model was used to identify factors associated with time to death.

Result: Median age of patients was 32.4 years with Inter Quartile Range (IQR) [15, 65]. The female to male ratio of the study participants' was 1.4:1. Median CD4 count significantly increased during the last four consecutive years of follow up. A total of $92(12.6 \%)$ patients died, 106(14.5\%) were lost to follow-up, and 109(15\%) were transferred out. Sixty three $(68 \%)$ deaths occurred in the first 6 months of treatment. The median survival time was 25 months with IQR $[9,43]$. After adjustment for confounders, WHO clinical stage IV [HR 2.42; $95 \%$ Cl, 1.19, 5.86], baseline CD4 lymphocyte counts of $201 \mathrm{cell} / \mathrm{mm}^{3}$ and $350 \mathrm{cell} / \mathrm{mm}^{3}$ [HR 0.20; $95 \% \mathrm{Cl} ; 0.09-0.43$ ], poor regimen adherence [HR $2.7095 \%$ Cl: 1.4096, 5.20], baseline hemoglobin level of 10gm/dl and above [HR 0.23; $95 \%$ Cl: 0.14, 0.37] and baseline functional status of bedridden [HR 3.40; $95 \% \mathrm{Cl}: 1.61,7.21]$ were associated with five year survival of HIV patients on ART.

Conclusion: All people living with HIV/AIDS should initiate ART as early as possible. Initiation of ART at the early stages of the disease, before deterioration of the functional status of the patients and before the reduction of CD4 counts and hemoglobin levels with an intensified health education on adherence to ART regimen is recommended.
\end{abstract}

\footnotetext{
*Correspondence: wondaay@gmail.com

'School of Public Health, Addis Ababa University, P.O. Box 9086, Addis Ababa, Ethiopia

Full list of author information is available at the end of the article
}

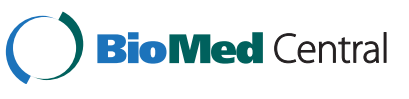

(C) 2015 Ayele et al. Open Access This article is distributed under the terms of the Creative Commons Attribution 4.0 International License (http://creativecommons.org/licenses/by/4.0/), which permits unrestricted use, distribution, and reproduction in any medium, provided you give appropriate credit to the original author(s) and the source, provide a link to the Creative Commons license, and indicate if changes were made. The Creative Commons Public Domain Dedication waiver (http://creativecommons.org/publicdomain/zero/1.0/) applies to the data made available in this article, unless otherwise stated. 


\section{Background}

An estimated 34.0 million adults worldwide were living with Human Immunodeficiency Virus (HIV) and of these 2.5 million were newly infected with the virus and 1.7 million died of HIV/ Acquired Immune Deficiency Syndrome (AIDS) in 2011 [1]. In Sub-Saharan Africa, more than 23.5 million people were living with HIV, 1.8 million become newly infected and 1.3 million died of (AIDS) at the end of 2011 [1].

HIV management is currently in an era of effective ART. In the last 29 years, modern drug discovery and have development has transformed HIV-1 disease into a treatable chronic infectious disease [2]. In 2009 alone, 1.2 million people received ART for the first time worldwide, an increase in the number of people receiving treatment by $30 \%$ in a single year. Overall, the number of people receiving therapy has grown 13-fold, more than five million people in low and middle-income countries, since 2004 [3].

Since 2005, the Ethiopian government in collaboration with its partners has been providing free antiretroviral drugs for eligible HIV/AIDS patients in order to reduce epidemics and improve the quality of life for those living with the virus. Of the more than 1.2 million individuals living with the virus, 397,818 were eligible in 2010/11 for antiretroviral treatment [4]. There were about 743 health facilities that provide ART for 333,434 HIV/AIDS patients in 2010/11 [4].

According to the 2011 Ethiopian Demographic and Health Survey, the national prevalence of adult HIV was 2.4 and $1.0 \%$ in SNNPR [5]. Regarding the distribution, urban areas had much higher prevalence (4.0\%) than rural areas $(0.6 \%)$. Moreover, the prevalence was higher among females (1.9\%) than males $1.0 \%$ [5].

The use of antiretroviral medicines has dramatically reduced AIDS related illnesses and death in countries where these drugs are widely accessible [6].

$\mathrm{HIV}$ incidence has fallen by more than $25 \%$ between 2001 and 2009 in 33 countries. Of these countries, 22 are from sub-Saharan Africa [3]. Early reports from ART programs in resource-limited settings have been promising, with virological efficacy comparable to industrialized countries [7]. Nevertheless, mortality has been high, particularly during the first months after initiating ART [7, 8]. While evidences have proven that ART improves the survival time and quality of life of HIV patients, several clinical and socio demographic factors contributing to this high mortality and poor treatment outcome are not well understood in Ethiopia. Hence, this study was designed to investigate the treatment outcomes and its determinants for HIV patients on ART in selected health facilities of Kembata and Hadiya zones,
Southern Nations, Nationalities and Peoples Region, Ethiopia.

\section{Methods}

\section{Study area and period}

The study was conducted in four selected health facilities from Kembata and Hadiya zones, South Nations, Nationalities and Peoples Region [SNNPR], Ethiopia. SNNPR is one of the largest regions in Ethiopia, accounting for more than 10 percent of the country's land area and the current population is approximately 17 million with an average household size of 4.8 in 2007. More than 91 percent of the SNNPR population lives in rural areas [9]. The mid-2010 population was estimated at nearly $17,745,000$ [10]. The region is divided into 13 administrative zones. But, this study was conducted in two Health Centers and two Zonal Hospitals of Kembata and Hadiya zones. Kembata Zone has ten districts and an estimated total population of 1.2 million. It has one zonal hospital, 30 functional public health centers and 262 health posts among which nine health centers and one zonal hospital are providing ART services for 986 ART patients [11]. Similarly, Hadiya Zone has 11 districts with an estimated total population of 1.5 million. It has one zonal hospital, 37 functional public health centers and 282 health posts among which ten health centers and one zonal hospital are providing ART service for 2367 ART patients. The health service coverage in the two zones is $100 \%$ [12]. The study was conducted from January to February, 2012.

\section{Study design}

A retrospective cohort study was conducted on people living with HIV/AIDS enrolled for ART services in two Health Centers and two Zonal Hospitals of Kambata and Hadiya zones from 2007 to 2011.

\section{Target and study population}

The target population was all adult HIV positive patients enrolled for ART services in SNNPR and the study population was all adult HIV positive patients enrolled on ART from December 2007- December 2011 in four selected health facilities of Kembata and Hadiya zones of SNNP Region. All HIV/AIDS patients who were 15 years old and above and enrolled on ART program for at least two clinical visits in the selected health facilities were included in the study. Patients who started treatment in other places and with incomplete baseline CD4 counts and basic personal information such as hemoglobin level and age were excluded.

\section{Sample and sampling technique}

Purposive sampling was used to include the two zones from the 13 zones of SNNPR. Currently there are 20 health facilities providing ART services in the study area. 
Among these, six health facilities (two hospital and four health centers) were eligible for this study. Eligible health facilities were stratified into hospital and health centers in each study zone and then one hospital was included from each zone. Since each zone had only one hospital, the two hospitals namely Durame Hospital from Kembata and Hossana Hospital from Hadiya were included as study sites. Among the two eligible health centers from each zone, the health center with the highest number of HIV patients (case load) on ART was selected. Thus, one hospital and one health center were selected from each zone to be included in the study. Finally all eligible patients (730) on ART from the four health facilities were included as study subjects.

\section{Standard and operational definition}

The main outcome variables were death and time to death in any of the five years follow up period. Secondary outcome variable (undesirable outcome) was time when patient was lost to follow up, stopped or dropped out any of the five years follow up period. Survival time was defined as the length of time between ART initiation and death/censure. The predictor (covariate) variables included in the model were socio demographic factors (age, sex, marital status, level of education, religion, residence, employment status, spouse health and ART enrollment condition), past and new opportunistic illness, WHO clinical stage, baseline CD4 cells count, baseline weight, hemoglobin, drug regimen, functional status, adherence to HIV medication, attendance of HIV related training, HIV prophylaxis, type of facility (health center, hospital), tobacco smoking, alcohol drinking and use of other substances.

\section{Data collection tools and procedures}

A structured data extraction format was adopted from ART intake and follow up forms of ART clinics. Six nurses were recruited and one for each health center and two for each hospital were assigned as data collators. Data was collected retrospectively from all eligible medical records of adult HIV/AIDS patients on ART from ART in take form and ART follow up forms.

\section{Data management and statistical analysis}

Data was entered, cleaned and coded and checked for missing values, outliers and inconsistencies using SPSS Version 16. To ensure data quality, data collectors were trained, pre-test was carried out at a health center with similar setting to the study health facilities, filled-in forms were checked for completeness and accuracy and corrected on daily basis before leaving the health facilities and $10 \%$ of data were re-entered and discrepancies reviewed by an independent person. Data analysis was carried out with STATA 11.
Descriptive statistical methods were used to summarize the socio-demographic and clinical characteristics of the study participants. The survival time was calculated in months using the time interval between date of ART initiation and 1) date of event (death) for events, 2) date of transfer for transferred out (TO), 3) first date of the first missed appointment for lost cases and 4) the date in which patient completed the 60 months (five years) follow up. For survival analysis two scenarios were considered separately, a real-case assumption (confirmed dead cases were used as events) and a worst-case assumption (lost cases were also considered as events). Descriptive survival statistical analysis (Kaplan-Meier) was used to estimate survival probability after ART initiation. Cox proportional hazards models were used to examine baseline factors associated with time to death. To evaluate the effects of covariate on patient survival, the Wald test was used to define the variables to be entered into the Cox proportional hazards model. Factors that were associated with time to death at $25 \%$ significant level in the bivariate analysis were included in the final Multivariate analysis. Then important predictor variables were identified by fitting the stepwise Cox's proportional hazard model to the data set. The results of the final model were expressed in terms of Hazard Ratio (HR) and 95 \% confidence intervals $(\mathrm{CI})$ and statistical significance was declared if the $\mathrm{p}$-value is less than 0.05 . The presence of potential confounding factors or interaction were diagnosed and treated accordingly. Finally Cox proportional hazards model goodness of fit were assessed by using Cox-Snell residual and Harrell's Concordance statistic test and the model was fitted accordingly to predicted response variable (Fig. 5).

Ethical clearance was obtained from the Institutional Review Board of the College of Health Sciences of Mekelle University. No information obtained from the medical records was disclosed to any third person. Patient identification variables such as name were not used in the study. This study did not inflict harm on or expose HIV/AIDS patients to unnecessary risk as a result of reviewing their medical records.

\section{Result}

Out of, 730 patients included in the analysis, 270(37\%) were initiated on ART in 2007, While 134(18 \%), $160(22 \%) 81(11 \%)$ and $85(12 \%)$ were initiated in 2008 , 2009, 2010 and 2011 respectively. The study findings revealed that 429 (59 \%) study subjects were females. The median age of the patients was 30 with IQR [26, 37] years. Of the study subjects, two-third of them were had no formal education or completed primary education at the time of initiation of their ART treatment. Almost $62 \%$ of the patients were unemployed at the time of initiation of ART and $51.4 \%$ of the patients were enrolled 
from urban districts. From a total of 730 patients, $178(24.4 \%)$ drink alcohol, 98 (13.4 \%) use other substances such as Khat and Shisha and 94 (12.9\%) smoke tobacco at initiation of ARV treatment (Table 1). From 730 patients, $481(65.9 \%)$ had opportunistic infections at the time of treatment initiation and $196(26 \%)$ patients developed opportunistic infections after initiation of ARV treatment.

Regarding the functional status of the patients, 495 (68 \%) were working, 194 (26.6\%) ambulatory and $39(5.4 \%)$ bedridden at the time of the start of ARV treatment. Moreover, 413 (57\%) were in WHO stage III, $148(20.4 \%)$ in stage II, 101 (14\%) patients were in stage I and $62(8.6 \%)$ patients were in stage IV at the time of ART initiation. Meanwhile, median [IQR] CD4 count was 151 [78, 224] cells $/ \mathrm{mm}^{3}$. Six hundred seventy five (92.5\%) patients had good, 18(2.4\%) fair and 37(5.1\%) poor adherence to recommended ART regimen (Table 2). Median weight [IQR] of patients at baseline was 51.5 [46 57.2] $\mathrm{kg}$ and had increased to $55 \mathrm{~kg}$ and $56.75 \operatorname{kg}(p=001)$ at first 6 and 12 months follow up, respectively (Fig. 1). Similarly, CD4 count significantly increased over the last four consecutive years of follow up. The median CD4-cell count at ART initiation was 151 cells $/ \mathrm{mm}^{3}$ which increased to 299 cells $/ \mathrm{mm}^{3}$ at 6 months, 353 cells $/ \mathrm{mm}^{3}$ at 12 months, 410 cells/ $\mathrm{mm}^{3}$ at 24 months, 464.5 cells $/ \mathrm{mm}^{3}$ at 36 months, 497 cells $/ \mathrm{mm}^{3}$ at 48 months and 488.5 cells $/ \mathrm{mm}^{3}$ at 60 months of follow up (Fig. 2).

\section{Descriptive survival analysis of patients during the follow up period}

The median [IQR] follow-up time was 25 [9, 43] months. A total of 92(12.6\%) patients died in the five years follow up period after initiation of ARV treatment. Among these, 63 (68\%) deaths occurred in the first 6 months of treatment, $70(76.1 \%)$ deaths occurred within one year follow up, 14(15.2\%) between one and two years of follow up and the rest $8(8.7 \%)$ deaths occurred between third and fifth years of follow up. Overall, $106(14.5 \%)$ patients were lost to follow-up and $109(14.9 \%)$ were transferred out to other heath facilities for treatment. The mortality rate during the follow-up period was $4 / 1000$ person-years. Survival function showed that the probability of surviving for real and worst case assumptions was 0.83 and 0.64 , respectively (Table 3). The survival function estimate graphs (Fig. 3) declined sharply at first six months follow up and then tailed off gradually. On the other side, the hazard estimate graphs (Fig. 4) sharply increased at the first six months of follow up. The initial sharp decline shows that there was high risk of dying during the first six months of follow up. The relatively long right tail was due to the few subjects who had long survival times.
The minimum value of the survivorship function was not zero since the largest observed time was a censored observation.

\section{Bivariate and multivariate analysis}

Bivariate analysis of the factors revealed that the risk of death in five years follow up was associated with sex, spouse treatment status, tobacco smoking, other substance use, Tuberculosis (TB) status before initiation of ART, OIs after initiation of ART, TB after initiation of ART, functional status, WHO clinical stage, hemoglobin, baseline CD4 cells count, baseline weight, baseline drug regimen and regimen adherence. Factors that were associated with time to death at $25 \%$ significant level in the bivariate analysis were included in the final multivariate analysis. According to the multivariate Cox model, the risk of death for patients with two or more opportunistic infections after initiation of ART was roughly three fold (hazard ratio, 3.353; 95 \% CI, 1.462- 7.691) as compared with patients who had no opportunistic infection following the initiation of ART. Similarly, those with WHO stage III and IV at ART initiation had increased risk of death [hazard ratio (HR) 2.01, 95 \% CI: 1.02,4.35; HR 2.42, (95 \% CI: 1.19, 5.86, respectively], when compared with WHO stage I. However, those with $51-200$ cells $/ \mathrm{mm}^{3}$, 201-350 cell $/ \mathrm{mm}^{3}$ and above $350 \mathrm{cell} / \mathrm{mm}^{3}$ baseline CD4 cell counts reduce the risk of death by 0.26 [95 \% CI; 0.15, 0.45], 0.198 [95\% CI; 0.09, 0.43] and 0.12 [95 \% CI; 0.02, 0.91], respectively as compared to patients with less than $51 \mathrm{cell} / \mathrm{mm}^{3} \mathrm{CD} 4$ counts. Patients with hemoglobin level of $10 \mathrm{~g} / \mathrm{dl}$ and above at initiation of ART had reduced a risk of death reduced by 0.22 [HR $0.22,95 \% \mathrm{CI}: 0.14,0.37]$ as compared to those whose hemoglobin level was less than $10 \mathrm{~g} / \mathrm{dl}$. The risk of death was 2.7 times higher for patients with poor regimen adherence (HR: 2.70, 95 \% CI: [1.40, 5.20] as compared to patient who had good regimen adherence. Similarly, patients with ambulatory and bedridden functional status had higher risk of dying (HR: 1.79; 95 \% CI: $[1.05,3.07])$ and (HR: 3.40, $95 \%$ CI: [1.61, 7.21]), respectively as compared with those working functional status at baseline (Table 4).

\section{Discussion and conclusions}

The proportion of female patients was significantly higher than the one of male patients. This might be due to the fact that women by their nature are highly vulnerable to HIV infection than their counterparts. Moreover, women may be more often diagnosed than men due to high frequency of testing for women as part of PMTCT program. Similar findings were reported from Hawassa referral hospital in SNNPR, Ethiopia [13]. Moreover, the findings of this study coincide with other studies conducted in Africa in terms of sex proportionality [14, 15]. 
Table 1 Description of demographic and behavioral characteristics of patients at baseline in Durame and Hosanna hospitals and Shinshicho and Hossana health centers, 2007-2011, $(n=730)$

\begin{tabular}{|c|c|c|c|}
\hline & Variable & Number & Percent \\
\hline \multirow[t]{2}{*}{ Sex } & Male & 301 & $41.2 \%$ \\
\hline & Female & 429 & $58.8 \%$ \\
\hline \multirow[t]{5}{*}{ Age at start of ART by years } & $15 \_24$ & 92 & $12.6 \%$ \\
\hline & 25_34 & 359 & $49.2 \%$ \\
\hline & $35 \_44$ & 197 & $27.0 \%$ \\
\hline & $45 \_54$ & 58 & $7.9 \%$ \\
\hline & $>54+$ & 24 & $3.3 \%$ \\
\hline \multirow[t]{5}{*}{ ART initiated by Years } & 2007 & 270 & $37.0 \%$ \\
\hline & 2008 & 134 & $18.0 \%$ \\
\hline & 2009 & 160 & $22.0 \%$ \\
\hline & 2010 & 81 & $11.0 \%$ \\
\hline & 2011 & 85 & $12.0 \%$ \\
\hline \multirow[t]{6}{*}{ Marital status } & Single & 94 & $12.9 \%$ \\
\hline & Married & 415 & $56.9 \%$ \\
\hline & Separated & 51 & $7.0 \%$ \\
\hline & Divorced & 58 & $8.0 \%$ \\
\hline & Widowed & 111 & $15.2 \%$ \\
\hline & Unknown & 1 & $0.001 \%$ \\
\hline \multirow[t]{4}{*}{ Level of education } & $\begin{array}{l}\text { Without formal } \\
\text { education }\end{array}$ & 161 & $22.1 \%$ \\
\hline & Primary & 315 & $43.2 \%$ \\
\hline & Secondary & 204 & $27.9 \%$ \\
\hline & Tertiary & 50 & $6.8 \%$ \\
\hline \multirow[t]{4}{*}{ Religion } & Orthodox & 176 & $24.1 \%$ \\
\hline & Muslim & 91 & $12.5 \%$ \\
\hline & Protestant & 445 & $61.0 \%$ \\
\hline & Catholic & 18 & $2.5 \%$ \\
\hline \multirow[t]{3}{*}{ Residence } & Urban & 374 & $51.4 \%$ \\
\hline & Rural & 354 & $48.6 \%$ \\
\hline & Unknown & 2 & $0.003 \%$ \\
\hline \multirow[t]{3}{*}{ Occupation } & Employed & 278 & $38.1 \%$ \\
\hline & Unemployed & 451 & $61.9 \%$ \\
\hline & Unknown & 1 & $0.001 \%$ \\
\hline \multirow[t]{4}{*}{ Condition of the husband/wife } & Healthy & 127 & $19.8 \%$ \\
\hline & Chronically ill & 155 & $24.1 \%$ \\
\hline & Dead & 148 & $23.0 \%$ \\
\hline & Unknown & 213 & $33.1 \%$ \\
\hline \multirow[t]{3}{*}{ Spouse treatment status } & Enrolled ART & 179 & $27.8 \%$ \\
\hline & Not Enrolled ART & 254 & $39.4 \%$ \\
\hline & Unknown & 212 & $32.9 \%$ \\
\hline
\end{tabular}

$32.9 \%$
Table 1 Description of demographic and behavioral characteristics of patients at baseline in Durame and Hosanna hospitals and Shinshicho and Hossana health centers, 2007-2011, $(n=730)$ (Continued)

\begin{tabular}{llll}
\hline Risk behavior at baseline & Drink alcohol & 178 & $24.4 \%$ \\
& $\begin{array}{l}\text { Smoke tobacco } \\
\text { Use other } \\
\text { substances }\end{array}$ & 94 & $12.9 \%$ \\
& $\begin{array}{l}\text { No use of any } \\
\text { substance }\end{array}$ & 360 & $13.4 \%$ \\
& Yes & $35.3 \%$ & $49 \%$ \\
Attending HIV related training & No & 372 & $51 \%$ \\
Understanding HIV prophylaxis & Good & 356 & $46 \%$ \\
& Poor & 374 & $54 \%$ \\
Understanding HIV medication & Good & 311 & $42 \%$ \\
adherence & Poor & 419 & $58 \%$ \\
\hline
\end{tabular}

About $12.2 \%$ of patients died during the five years follow up period and $68 \%$ of the deaths occurred within the first six months of follow up. This was higher than $11.2 \%$ death after 24 months of follow up reported in the retrospective longitudinal study from Ethiopia [16]. The overall death in the five year follow up study was lower compared to $29.7 \%$ death after three years of follow up from Cameroon [17] and $28.5 \%$ from Tanzania [18] who died after five years of ART follow up. However, the total death in our finding was slightly higher than the two years follow up study conducted in Shashamene and Assela Hospitals [10.2 \%] from Ethiopia [19]. This could be explained by the fact that our study was based on five years of survival compared to the two years of survival analysis [19].

The higher mortality in the first few months of therapy in our set up was similar to other studies reported from different African countries [17-20]. This may partly be explained by the fact that most of the patients had CD4 count less than 200 cells $/ \mathrm{mm}^{3}$ at the time of ART initiation and were at an advanced WHO stages [III and IV]. More than half of the patients did not attend any kind of HIV related education and had no idea about prophylaxis. Besides, $48.6 \%$ of them were from rural areas, where access to information and Volunteer counseling and testing services were highly limited during initiation of ART. These might have been the factors responsible for delayed diagnosis which in turn has led to high early mortality. Other study results from South Africa showed that one or more opportunistic diseases and immune reconstitution inflammatory syndrome were the major causes of death at early initiation of ART [21].

Lost to follow up was found to be high, 106(14.5\%). Most of the lost to follow up cases occurred within six 
Table 2 Clinical characteristics of patients in four selected health facilities of Kembata and Hadiya zones, 2007-2011 ( $n=730)$

\begin{tabular}{|c|c|c|c|}
\hline Variables & & Number & Percents \\
\hline \multirow[t]{3}{*}{$\begin{array}{l}\text { Opportunistic illness } \\
\text { before initiation of ART }\end{array}$} & $\begin{array}{l}\text { Had above one } \\
\text { opportunistic infections }\end{array}$ & 201 & $27.5 \%$ \\
\hline & $\begin{array}{l}\text { Had one opportunistic } \\
\text { infection }\end{array}$ & 280 & $38.4 \%$ \\
\hline & $\begin{array}{l}\text { No opportunistic } \\
\text { Infection }\end{array}$ & 249 & $34.1 \%$ \\
\hline \multirow[t]{3}{*}{$\begin{array}{l}\text { Opportunistic illness after } \\
\text { initiation of ART }\end{array}$} & $\begin{array}{l}\text { Had above one } \\
\text { opportunistic infections }\end{array}$ & 26 & 3.5 \\
\hline & $\begin{array}{l}\text { Had one opportunistic } \\
\text { infection }\end{array}$ & 170 & 23.3 \\
\hline & $\begin{array}{l}\text { No opportunistic } \\
\text { infection }\end{array}$ & 534 & 73.2 \\
\hline \multirow[t]{2}{*}{ CPT prophylaxis } & Present & 461 & $63.2 \%$ \\
\hline & Absent & 269 & $36.8 \%$ \\
\hline \multirow[t]{4}{*}{ Functional status } & Working & 495 & $68 \%$ \\
\hline & Bedridden & 39 & $5.4 \%$ \\
\hline & Ambulatory & 194 & $26.6 \%$ \\
\hline & Unknown & 2 & $0.003 \%$ \\
\hline \multirow[t]{5}{*}{ WHO clinical stage } & Stage I & 101 & $14.0 \%$ \\
\hline & Stage II & 148 & $20.4 \%$ \\
\hline & Stage III & 413 & $57.0 \%$ \\
\hline & Stage IV & 62 & $8.6 \%$ \\
\hline & Unknown & 2 & $0.003 \%$ \\
\hline \multirow[t]{2}{*}{ Hemoglobin (g/dl) } & $<10$ & 110 & $15.1 \%$ \\
\hline & $\geq 10$ & 620 & $84.9 \%$ \\
\hline \multirow[t]{4}{*}{ CD4 counts at baseline } & $\leq 50$ cells $/ \mathrm{mm}^{3}$ & 106 & $14.5 \%$ \\
\hline & $51-200$ cells $/ \mathrm{mm}^{3}$ & 398 & $54.5 \%$ \\
\hline & $201-350 \mathrm{cell} / \mathrm{mm}^{3}$ & 195 & $26.7 \%$ \\
\hline & $>350 \mathrm{cell} / \mathrm{mm}^{3}$ & 31 & $4.2 \%$ \\
\hline \multirow[t]{4}{*}{ Weight at baseline } & $\leq 45$ & 160 & $21.9 \%$ \\
\hline & $46-55$ & 329 & $45.1 \%$ \\
\hline & $56-65$ & 184 & $25.2 \%$ \\
\hline & $>65$ & 57 & $7.8 \%$ \\
\hline \multirow[t]{6}{*}{ Regimen at baseline } & $1 \mathrm{a}=\mathrm{d} 4 \mathrm{t}-3 \mathrm{TC}-\mathrm{NVP}$ & 268 & $37.0 \%$ \\
\hline & $1 b=d 4 t-3 T C-E F V$ & 67 & $9.3 \%$ \\
\hline & $1 \mathrm{C}=\mathrm{AZT}-3 \mathrm{TC}-\mathrm{NVP}$ & 197 & $27.2 \%$ \\
\hline & $1 d=A Z T-3 T C-E F V$ & 51 & $7.0 \%$ \\
\hline & TDF-3TC_NVP & 141 & $19.5 \%$ \\
\hline & Unknown & 6 & $0.008 \%$ \\
\hline \multirow[t]{3}{*}{ Regimen adherence } & Good & 675 & 92.5 \\
\hline & Fair & 18 & 2.4 \\
\hline & Poor & 37 & 5.1 \\
\hline
\end{tabular}

Table 2 Clinical characteristics of patients in four selected health facilities of Kembata and Hadiya zones, 2007-2011 ( $n=730)$ (Continued)

\begin{tabular}{llll}
\hline Treatment outcome & On treatment & 423 & $57.9 \%$ \\
& Dead & 92 & $12.6 \%$ \\
Stopped & 4 & $.5 \%$ \\
Lost & 17 & $2.3 \%$ \\
& Transfer out & 109 & $14.9 \%$ \\
& Drop & 85 & $11.6 \%$ \\
\hline
\end{tabular}

months of starting ART. This was lower than the national dropout estimate of $21.3 \%$ from Ethiopia [22]. Moreover, lost to follow up was higher when compared to other studies in Africa. Studies from Cameroon and Tanzania reported that 5 and $9.7 \%$ lost in the two years follow up periods, respectively $[17,18]$. The longer follow up period is believed to be the reason for the high lost to follow up rate in our study. The addictive behavior of the patients, drug side effect, absence of tangible information on the enrolment of spouses and long distance travel to take medicines might have discouraged the patients to miss follow ups. Moreover, the lost cases in our context had probably been dead but were not reported due to poor patient tracing and reporting mechanisms of the recent scaled up services of the study facilities. The lack of National death registration has limited the capacity of tracing lost cases for possible confirmation of outcome [22].

WHO clinical stage of disease was a strong predictor of mortality in this study. Patients with advanced WHO clinical stages III and IV had nearly twice higher risk of dying during the five years survival as compared with reference group of WHO clinical stage I. Several studies from Africa including Ethiopia have shown that advanced WHO stage III and IV was a strong predictor of mortality in patients on ART, even after controlling for CD4 cell count [19, 23-26]. The possible reason for the higher risk of death in patients with advanced clinical disease stages III and IV could be the increased susceptibility for contracting opportunistic infections among this group.

The five years survival analyses result showed that patients who started ART with lower CD4 cells count had an increased risk of death compared to those who started with higher CD4 cell counts. The improved rate of survival among patients who initiated antiretroviral therapy at higher CD4 cells count probably can be attributed to multiple factors, including earlier control of viral replication and viral diversity and a greater immunologic benefit [27]. These findings are in line with numerous study findings from resource-limited settings showing low baseline CD4 cell count was a major predictor of death, and waiting ART until the CD4 cell 


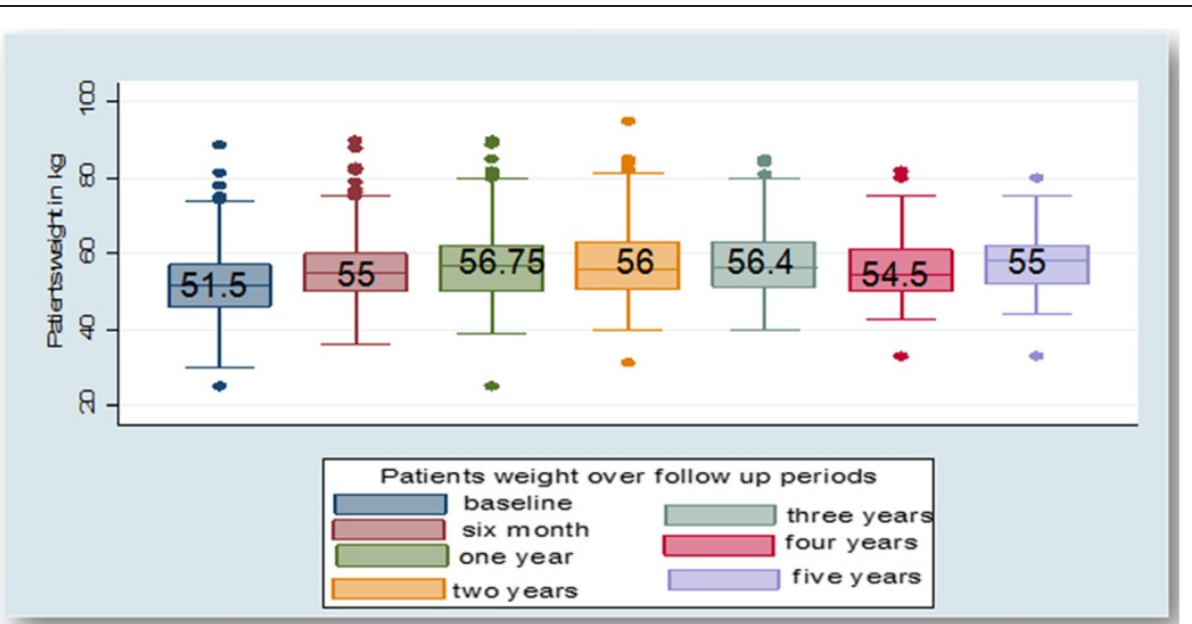

Fig. 1 Progressive change in median weight over the follow up period in four selected health facilities of Kembata and Hadiya zones of SNNPR, Ethiopia [2007-2011]

count falling below 350 cells $/ \mathrm{mm}^{3}$ was associated with increased morbidity and mortality [28, 29]. Similarly, findings from the developed world suggested that starting ART at higher CD4 cell counts improved treatment outcomes and decreases mortality [25,30]. Moreover, recent three years survival analysis result from Hawassa referral Hospital of SNNPR, Ethiopia has showed that patients with $\mathrm{CD}_{4}$ count below 50 cells $/ \mathrm{mm}^{3}$ had higher risk of death [10].

Hemoglobin values at baseline were strongly associated with the risk of death. Similar study findings were reported from Tanzania [18] and Ethiopia [13, 19]. Anemia could be an indicator of advanced disease or clinical feature of some opportunistic infections which might aggravate risk of death. Furthermore, anemia can be a feature of certain opportunistic diseases, like disseminated mycobacterial infection and parvovirus B19 [31]. Several other etiologic factors may be involved in the development of HIV-associated anemia, including micronutrient deficiencies, immunological myelosuppression, impaired erythropoietin production and blood loss from intestinal opportunistic disease [31].

Baseline functional status was strongly associated with five years survival time. The risk of death for those who started ART at baseline with bedridden functional status was twice higher than those who started ART

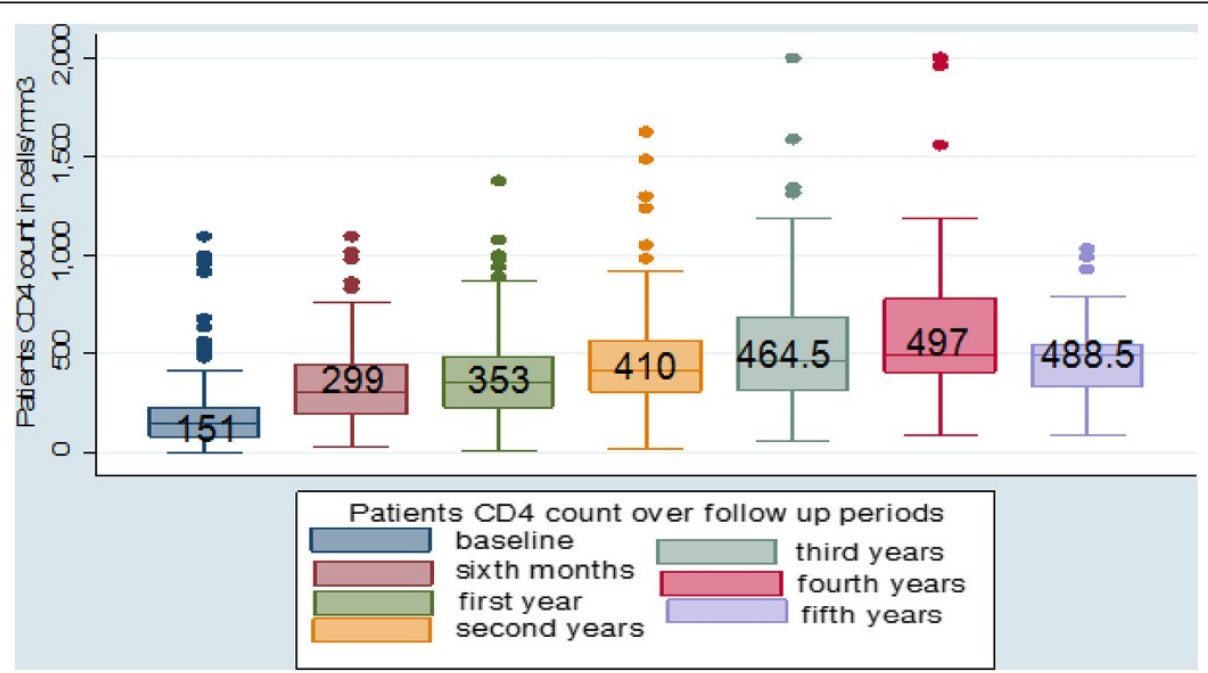

Fig. 2 Progressive change in median CD4 Counts over the follow up period in four selected health facilities of Kembata and Hadiya zones of SNNPR, Ethiopia [2007-2011] 
Table 3 Kaplan Meier estimator of survival functions of event for both real and worst case assumptions of different follow up periods

\begin{tabular}{lllllll}
\hline $\begin{array}{l}\text { Follow up time } \\
\text { (month) }\end{array}$ & $\begin{array}{l}\text { Events } \\
\text { (death) }\end{array}$ & $\begin{array}{l}\text { Survival } \\
\text { function }\end{array}$ & $\begin{array}{c}95 \% \text { confidence } \\
\text { interval }\end{array}$ & $\begin{array}{l}\text { Events } \\
\text { (worst cases) }\end{array}$ & $\begin{array}{l}\text { Survival } \\
\text { function }\end{array}$ & $\begin{array}{c}95 \% \text { confidence } \\
\text { interval }\end{array}$ \\
\hline 1 & 16 & 0.98 & {$[0.96,0.99]$} & 18 & 0.97 & {$[0.96,0.98]$} \\
3 & 25 & 0.94 & {$[0.92,0.96]$} & 31 & 0.93 & {$[0.91,0.95]$} \\
6 & 22 & 0.91 & {$[0.89,0.93]$} & 38 & 0.88 & {$[0.85,0.90]$} \\
12 & 7 & 0.90 & {$[0.87,0.92]$} & 32 & 0.83 & {$[0.80,0.85]$} \\
24 & 14 & 0.87 & {$[0.84,0.89]$} & 48 & 0.74 & {$[0.71,0.78]$} \\
36 & 2 & 0.87 & {$[0.84,0.89]$} & 27 & 0.71 & {$[0.67,0.74]$} \\
48 & 4 & 0.85 & {$[0.81,0.88]$} & 4 & 0.67 & {$[0.63,0.71]$} \\
60 & 2 & 0.83 & {$[0.79,0.87]$} & 18 & 0.64 & {$[0.59,0.69]$} \\
\hline
\end{tabular}

with working functional status. Similarly, recent study finding from Hawassa referral Hospital, SNNPR Ethiopia has showed that patients with bedridden functional status had higher risk of death as compared to those with working functional status [13]. However, there is limited data from Africa trying to explain higher mortality rates among the patients with functional status. The higher risk of death among patients with bedridden functional status could be the increased susceptibility for opportunistic infections and other clinical complications including bedsore, thrombosis, malnutrition, chronic illness and anorexia.

Patients with poor regimen adherence had increased risk of death [HR 2.695, 95 \% CI: 1.396-5.203] as compared with those who had good adherence of regimen. Medication adherence is critically important to achieve viral suppression and to avoid the emergence of viral resistance. The presence of more than one opportunistic infection after ART initiation had also an effect on the five year survival. Those patients diagnosed as having two or more opportunistic infections after ART initiation, had a much greater likelihood of dying than those who had no or only one opportunistic infection. Similarly, numerous study results from different settings have revealed that opportunistic infection after ART initiation had resulted in increased risk of death [16, 22, $32,33]$. The fact that patients develop opportunistic infections after ART is an indication of treatment failure and poor immunological response of ART which might lead to higher mortality. Moreover, in this study opportunistic infection after ART could be immune reconstitution

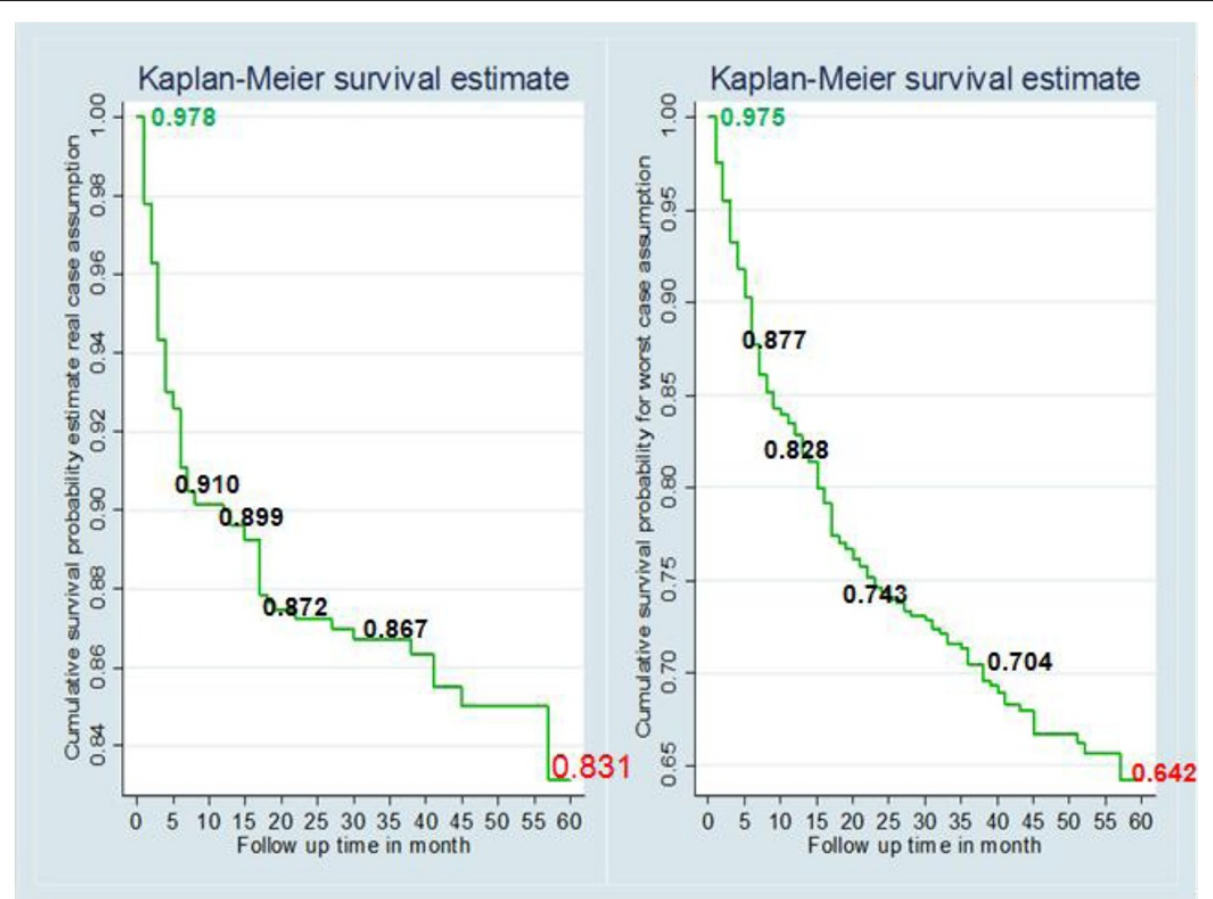

Fig. 3 Cumulative survivals for real (death) and worst case (lost) assumptions of patients during follow up periods in four selected health facilities of Kembata and Hadiya zones of SNNPR, Ethiopia, 2007-2011 


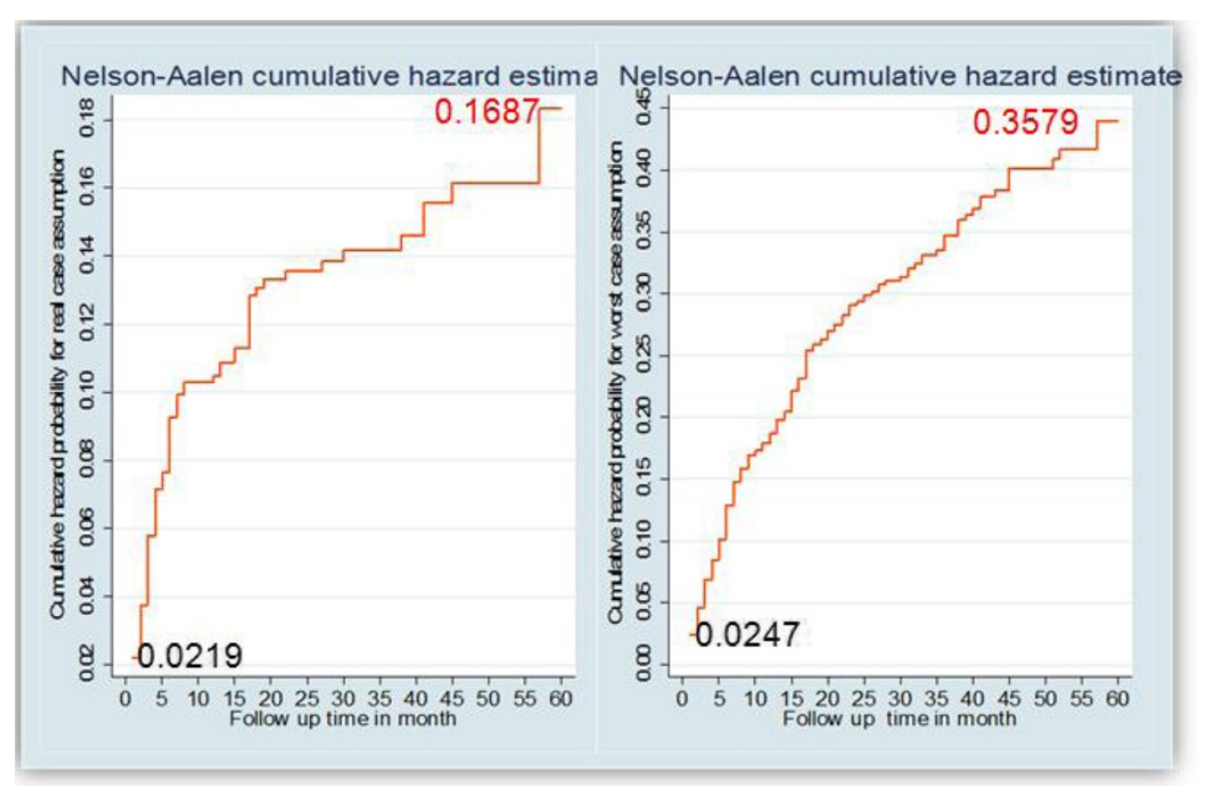

Fig. 4 Cumulative Hazard function for real and worst case assumptions during follow up periods in four selected health facilities of Kembata and Hadiya zones of SNNPR, Ethiopia, 2007-2011

inflammatory syndrome which has been shown to be one of the causes of mortality in HIV/AIDS patients on ART [21]. Pulmonary TB infection after ART initiation has statistically significant association with the risk of death. A study from three specialized hospitals of Oromia region, Ethiopia, revealed that TB/HIV coinfected patients had a lower quality of life as compared with those HIV infected patients without TB infection [34].

Our study findings revealed that CD4 count and weight were significantly increased after initiation of ART at five years survival time. Similarly, numerous study results from different settings revealed that CD4 count and weight of patient were increased after initiation of ART [14, 15, 17].

This five years survival analysis, in both models, sex, age, body weight, past opportunistic infection, place of residence, religious affiliation, facilities of care and level of education, marital status, risk behaviors such smoking tobacco and use of other substances were not statistically significant in multivariate analysis. Similar results were reported in different studies conducted in developing countries (37, 40,46_47).

The collection of data from large number of patients, inclusion of ART services at different health facility

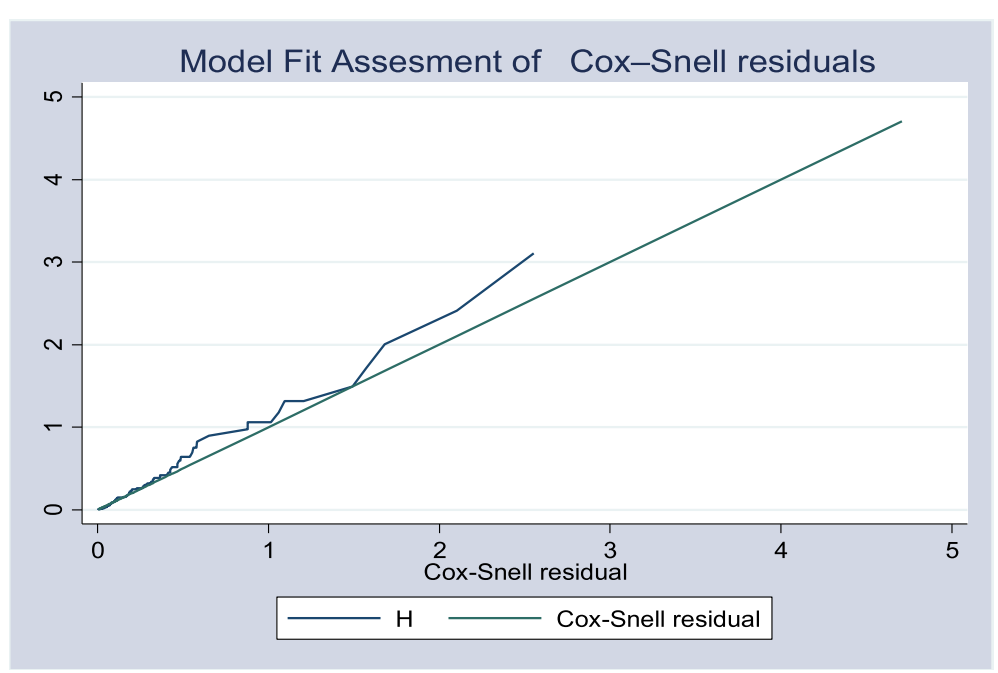

Fig. 5 Overall model fit of the Cox regression using the Cox-Snell residuals 
Table 4 Bivariate and Multivariate analysis for baseline clinical characteristics of patients in four selected health facilities of Kembata and Hadiya zones for Death (real case assumptions), 2007 - 2011

\begin{tabular}{|c|c|c|c|}
\hline Characteristics real case & $N$ & $\begin{array}{l}\text { Bivariate analysis } \\
\text { Hazard ratio7 }(95 \% \mathrm{Cl})\end{array}$ & $\begin{array}{l}\text { Multivariate analysis } \\
\text { Hazard ratio }(95 \% \mathrm{Cl})\end{array}$ \\
\hline \multicolumn{4}{|l|}{ Sex } \\
\hline Female & 429 & 1 & 1 \\
\hline Male & 301 & $1.69(1.69,2.12)$ & $1.22(0.70,2.10)$ \\
\hline \multicolumn{4}{|l|}{ Spouse treatment status } \\
\hline Enrolled ART & 179 & 1 & 1 \\
\hline Not Enrolled ART & 254 & $2.54(1.26,5.13)$ & $1.31(0.29,5.98)$ \\
\hline Unknown & 212 & $2.88(1.41,5.85)$ & $1.32(0.61,2.86)$ \\
\hline \multicolumn{4}{|l|}{ Smoke Tobacco } \\
\hline No & 636 & 1 & 1 \\
\hline Yes & 94 & $1.70(1.00,2.87)$ & $0.40(0.12,1.36)$ \\
\hline \multicolumn{4}{|l|}{ Use other substances } \\
\hline No & 631 & 1 & 1 \\
\hline Yes & 98 & $1.87(1.13,3.09)$ & $1.12(0.66,1.54)$ \\
\hline \multicolumn{4}{|c|}{ Attending HIV related education } \\
\hline No & 372 & 1 & 1 \\
\hline Yes & 358 & $0.68(0.44,1.05)$ & $0.87(0.66,1.90)$ \\
\hline \multicolumn{4}{|c|}{ Understanding HIV prophylaxis } \\
\hline Poor & 374 & 1 & 1 \\
\hline Good & 356 & $0.70(0.46,1.06)$ & $0.65(0.45,1.89)$ \\
\hline \multicolumn{4}{|c|}{ Understanding of Adherence to HIV medication } \\
\hline Poor & 419 & 1 & 1 \\
\hline Good & 311 & $0.68(0.44,1.05)$ & $0.68(0.38,1.44)$ \\
\hline \multicolumn{4}{|l|}{ Ols before initiation of ART } \\
\hline No Ols & 249 & 1 & \\
\hline Only one Ols & 280 & $1.27(0.78,2.07)$ & NA \\
\hline$\geq 2$ Ols & 201 & $0.73(0.44,1.23)$ & NA \\
\hline \multicolumn{4}{|c|}{ TB status before initiation of ART } \\
\hline Absent & 711 & 1 & \\
\hline Present & 19 & $3.33(1.54,7.20)$ & $1.25(0.68,1.54)$ \\
\hline \multicolumn{4}{|l|}{ Ols after initiation of ART } \\
\hline No Ols & 534 & 1 & 1 \\
\hline Only one Ols & 170 & $2.38(1.51,3.75)$ & $1.24(1.06,1.89)$ \\
\hline$\geq 2 \mathrm{Ols}$ & 26 & $10.90(6.13,19.37)$ & $3.35(1.46,7.69)$ \\
\hline \multicolumn{4}{|l|}{ TB after initiation of ART } \\
\hline Absent & 662 & 1 & 1 \\
\hline Present & 68 & $1.82(1.03,3.22)$ & $1.428(1.28,3.39)$ \\
\hline \multicolumn{4}{|l|}{ Past prophylaxis } \\
\hline Not Received & 269 & 1 & \\
\hline Received & 461 & $0.88(0.59,1.33)$ & NA \\
\hline \multicolumn{4}{|l|}{ Functional status } \\
\hline Working & 495 & 1 & 1 \\
\hline Ambulatory & 194 & $2.81(1.79,4.41)$ & $1.79(1.05,3.07)$ \\
\hline Bedridden & 39 & $6.32(3.42,11.700)$ & $3.40(1.61,7.21)$ \\
\hline
\end{tabular}


Table 4 Bivariate and Multivariate analysis for baseline clinical characteristics of patients in four selected health facilities of Kembata and Hadiya zones for Death (real case assumptions), 2007 - 2011 (Continued)

\begin{tabular}{|c|c|c|c|}
\hline \multicolumn{4}{|l|}{ WHO clinical stage } \\
\hline Stage I & 101 & 1 & 1 \\
\hline Stage ॥ & 148 & $2.32(0.64,8.41)$ & NA \\
\hline Stage III & 413 & $5.06(1.59,16.13)$ & $2.01(1.02,4.35)$ \\
\hline Stage IV & 62 & $8.58(2.46,19.87)$ & $2.42(1.19,5.86)$ \\
\hline \multicolumn{4}{|l|}{ Hemoglobin by $\mathrm{g} / \mathrm{dl}$} \\
\hline$<10$ & 110 & 1 & 1 \\
\hline$\geq 10$ & 620 & $0.17(0.11,0.26)$ & $0.22(0.14,0.37)$ \\
\hline \multicolumn{4}{|c|}{ CD4 counts at baseline } \\
\hline$<51$ cells $/ \mathrm{mm}^{3}$ & 106 & 1 & 1 \\
\hline $51-200$ cells $/ \mathrm{mm}^{3}$ & 398 & $0.23(0.15,0.35)$ & $0.26(0.15,0.45)$ \\
\hline $201-350 \mathrm{cell} / \mathrm{mm}^{3}$ & 195 & $0.13(0.07,0.25)$ & $0.20(0.09,0.43)$ \\
\hline$>350 \mathrm{cell} / \mathrm{mm}^{3}$ & 31 & $0.06(0.01,0.46)$ & $0.12(0.02,0.91)$ \\
\hline \multicolumn{4}{|l|}{ Weight at baseline } \\
\hline$\leq 45$ & 160 & 1 & 1 \\
\hline $46-55$ & 329 & $0.58(0.37,0.93)$ & $0.52(0.29,1.93)$ \\
\hline $56-65$ & 184 & $0.39(0.21,0.70)$ & $0.51(0.28,1.18)$ \\
\hline$>65$ & 57 & $0.24(0.07,0.75)$ & $0.55(0.16,1.19)$ \\
\hline \multicolumn{4}{|l|}{ Regimen at baseline } \\
\hline $1 \mathrm{a}=\mathrm{d} 4 \mathrm{t}-3 \mathrm{TC}-\mathrm{NVP}$ & 268 & 1 & 1 \\
\hline $1 b=d 4 t-3 T C-E F V$ & 67 & $0.71(0.32,1.58)$ & NA \\
\hline $1 \mathrm{C}=\mathrm{AZT}-3 \mathrm{TC}-\mathrm{NVP}$ & 197 & $0.55(0.31,0.97)$ & $1.63(0.87,3.05)$ \\
\hline $1 d=A Z T-3 T C-E F V$ & 51 & $0.84(0.36,1.98)$ & NA \\
\hline TDF-3TC_NVP & 141 & $1.39(0.82,2.35)$ & NA \\
\hline \multicolumn{4}{|l|}{ Regimen Adherence } \\
\hline Good & 675 & 1 & 1 \\
\hline Fair & 18 & $4.36(2.00,9.50)$ & $1.66(0.59,4.62)$ \\
\hline Poor & 37 & $5.94(3.49,10.14)$ & $2.70(1.40,5.20)$ \\
\hline
\end{tabular}

Ols Opportunistic infection

NA Not available

levels (hospitals and health centers) as opposed to the hospital studies from Ethiopia [13, 19, 32], inclusion of all eligible patient cards from the study facilities and use of individual level data were some of the strengths of this study. However, the study has limitations as well, since secondary data was used for statistical analyses, exploring a wide range of possible predictors for treatment outcomes was not possible. Thus, it was not possible to measure some important predictors such as nutritional status, viral loads and other important variables established as predictors of morbidity and mortality in patients on ART [21]. Retrospective nature of the study possibly introduces bias as the quality of information obtained from these finding is highly dependent on the completeness of patient records. Moreover, these findings were limited to Ethiopia and the first five years of ART.

\section{Conclusion}

The high early mortality have practical implications for addressing the need to initiate ART early which would require early diagnosis of HIV and might be addressed with improved counseling and testing services at facilities with strong community education and mobilization. The various baseline factors including WHO staging, CD4 counts, functional status, regimen adherence and hemoglobin level have significant effect on five years survival. Substantial efforts need to be made to move patients into care earlier in their disease progression in order to obtain the maximum benefit from ART. CD4 counts and weight of the patients were significantly increased at different follow up period. Health care providers should give serious attention to the identification of HIV opportunistic infections during initiation of ART which could contribute 
to reducing early death. In conclusion, all people living with HIV/AIDS should initiate ART as early as possible. Initiation of ART at the early stages of the disease and before the deterioration of the functional status of the patients and before the reduction of CD4 counts and hemoglobin levels with an intensified health education on adherence to ART regimen is recommended.

\section{Abbreviations}

AIDS: Acquired Immune Deficiency Syndrome; ART: Anti retroviral treatment; HIV: Human Immunodeficiency Virus; HR: Hazard ratio; IQR: Inter quartile range; SNNPR: South Nation Nationalities and Peoples Region;

TB: Tuberculosis.

\section{Competing interests}

The author(s) declare that they have no competing interests

\section{Authors' contributions}

WA: initiation of the study, design, implementation, analysis, interpretation of results and manuscript writing. AM: design, implementation, analysis, interpretation of results and writing the manuscript. AD: design, implementation, interpretation of results and writing the manuscript. FR: design, implementation, interpretation of results and writing the manuscript. All authors read and approved the final manuscript.

\section{Acknowledgement}

The authors would like to acknowledge Tulane International and Mekelle University for providing financial support to conduct the study and the data collectors and the health facilities for their cooperation.

\section{Author details}

'School of Public Health, Addis Ababa University, P.O. Box 9086, Addis Ababa, Ethiopia. ${ }^{2}$ Department of Public Health, Mekelle University, Mekelle, Ethiopia. ${ }^{3}$ Department of Public Health, Tulane University, New Orleans, LA, USA.

Received: 4 February 2014 Accepted: 21 August 2015

Published online: 27 August 2015

\section{References}

1. UNAIDS: Report on the Global AIDS epidemic. Geneva; 2012. http://www.unaids.org/sites/default/files/media_asset/ 20121120_UNAIDS_Global_Report_2012_with_annexes_en_1.pdf (accessed march 2012)

2. Patel KK, Patel AK. Future Implications: Compliance and Failure with antiretroviral therapy. J Post Grad Med. 2006:52(33):197.

3. World Health Organization (WHO). Towards universal accessing. Scaling up priority HIV/AIDS intervention in the health sector. Progress report. Geneva: WHO; 2010

4. Federal Democratic Republic of Ethiopia Minstry of Health: Health Sector Development Program IV: Annaual Health Performance report. Addis Ababa; [2010/11].

5. Central Statistical Agency [Ethiopia] and ICF International. Ethiopia Demographic and Health Survey 2011. Addis Ababa, Ethiopia and Calverton, Maryland, USA: Central Statistical Agency and ICF International; 2012.

6. UNAIDS/WHO. Report on the global HIV/AIDS Epidemic. Geneve; 2007. http://data.unaids.org/pub/EPISlides/2007/2007_epiupdate_en.pdf(accessed march 2012)

7. Ivers $L C$, Kendrick D, Doucette K. Efficacy of antiretroviral therapy programs in resource-poor settings: a meta-analysis of the published literature. Clin Infect Dis. 2005;41:217-24.

8. Etard JF, Ndiaye I, Thierry-Mieg M, Gueye NF, Gueye PM, Laniece I, et al. Mortality and causes of death in adults receiving highly active antiretroviral therapy in Senegal: a 7-year cohort study. AIDS. 2006;20:1181-9.

9. CSA. Statistical Tables: South Nation Nationalities and peoples Region. 2007 Retrievedfrom:http://www.csa.gov.et/index.php?option=com rubberdoc\&view=category\&id=72\&ltemid=521 (Accessed on March 20, 2012).

10. South Nation Nationalities Health Bureau. Health Sector Development program IV, Annual Health performance report. Hawassa; [2010/2011].
11. Kembata zone Health Department, Health Sector Development program IV: Annual Health performance report. Durame Kembata Zone Health Department; [2010/2011].

12. Hadiya zone Health Department: Health Sector Development program IV: Annual Health performance report. Hossana Hadiya Zone Health Department; [2010/2011].

13. Asressie M, Yigzaw K, Telake A. Outcomes of Antiretroviral Treatment Program at Referral Teaching Hospital on Hawassa south Ethiopia [Abstract]. Addis Ababa, Ethiopia Public health association; 2012.

14. Anne I, Goldman P, Carlin R, Crane L, Joyce K, Lawrence D, et al. Response of CD4 lymphocytes and clinical consequences of treatment using ddl or ddC in patiens with advanced HIV infection. J Acquir Immune Defic Syndr Hum Retrovirol. 1996;11(2):161-9.

15. Sentinel surveillance of HIV and AIDS in Kenya 2006. Nairobi: National AIDS Control Council, National AIDS/STI Control Programme, 2007

16. Assefa Assefa Y, Kiflie A, Tesfaye D, Haile Mariam D, Helmut K Wouters E et al. Outcomes of Anti Retroviral Treatment program in Ethiopia: Retention of Patients in Care is A Major Challenge and Varies across Health Facilities. BMC Health Services Research 2011. Retrieved from: http:// www.biomedcentral.com/1472-6963/11/81 (accessed on May 12, 2012).

17. Sieleunou I, Souleymanou M, Schonenberger AM, Menten J, Boelaert M. Determinants of survival in AIDS patients on antiretroviral therapy in a rural centre in the Far-North Province, Cameroon. Trop Med Int Health. 2009:4(1):36-43.

18. Johannessen A, Naman E, Ngowi BJ, Sandvik L, Matee Ml, Aglen HE, et al. Predictors of mortality in HIV-infected patients starting antiretroviral therapy in a rural hospital in Tanzania. BMC Infect Dis. 2008:8:52.

19. Alemu AW, Sebastian MS. Determinants of survival in adult HIV patients on antiretroviral therapy in Oromiyaa, Ethiopia. Global Health Action. 2010;3:5398 - doi:10.3402/gha.v3i0.5398

20. Fatti G, Grimwood A, Bock P. Better Antiretroviral Therapy Outcomes at Primary Healthcare Facilities: An Evaluation of Three Tiers of ART Services in Four South African Provinces. PLoS ONE. 2010;5(9):e12888. doi:10.1371/journal.pone.0012888.

21. Lawn SD, Myer L, Orrell C, Bekker LG, Wood R. Early mortality among adults accessing a community-based antiretroviral service in South Africa: implications for programme design. AIDS. 2005;19:2141-8.

22. Kloos H, Assefa Y, Adugna A, Mulatu MS, Mariam DH. Utilization of antiretroviral treatment in Ethiopia between February and December 2006: spatial, temporal, and demographic patterns. Int J Health Geogr. 2007:6:45.

23. Braitstein P, Brinkhof MW, Dabis F, Schechter M, Boulle A, Boulle A, Miotti P, Wood R et al. Mortality of HIV-1- infected patients in the first year of antiretroviral therapy: Comparison between low-income and high-income countries. Lancet. 2006;367:817-24.

24. Ferradini L, Jeannin A, Pinoges L, Izopet J, Odhiam Bo D, Mankhambo L. Scaling up of highly active antiretroviral therapy in a rural district of Malawi: an effectiveness assessment. Lancet. 2006;367(9519):1335-42.

25. Kitahata MM, Gange SJ, Abraham AG, Merriman B, Saag MS, Justice AC, et al. Effect of early versus deferred antiretroviral therapy for HIV on survival. N Engl J Med. 2009;360:1815-26.

26. Makombe SD, Jahn A, Tweya H, Chuka S, Yu JK-L, et al. A National Survey of Teachers on Antiretroviral Therapy in Malawi: Access, Retention in Therapy and Survival. PLoS ONE. 2007;2(7):e620. doi:10.1371/journal.pone.0000620.

27. Theys K, Deforche K, Vercauteren J, et al. Treatment-associated polymorphisms in protease are significantly associated with higher viral load and lower CD4 count in newly diagnosed drug-naive HIV-1 infected patients. Retro Virology. 9:81. 2012, retrieved from http:// www.retrovirology.com/content /9 / 81 (accessed on March 12, 2012).

28. Fox et al. Initiating patients on antiretroviral therapy at CD4 cell counts above $200 \mathrm{cell} / \mathrm{s} / \mathrm{ml}$ is associated with improved treatment outcomes in South Africa. AIDS. 2010;24(13):2041-2050.

29. Sterne JA, May M, Costagliola D, et al. Timing of initiation of antiretroviral therapy in AIDS-free HIV-1-infected patients: a collaborative analysis of 18 HIV cohort studies. Lancet. 2009;373:1352-63.

30. Kaplan JE, Hanson DL, Cohn DL, Karon J, Buskin S, Thompson M, et al. When to begin highly active antiretroviral therapy? Evidence supporting initiation of therapy at CD4R lymphocyte counts $<350$ cells/microl. Clin Infect Dis. 2003;37:951-8.

31. Semba RD, Gray GE. Pathogenesis of anemia during human immunodeficiency virus infection. J Investig Med. 2001:Volume 49 -Issue 3 -P 225-239. 
32. Mulissa Z, Jerene D, Lindtjørn B. Patients Present Earlier and Survival Has Improved, but Pre ART Attrition Is High in a Six-Year HIV Cohort Data from Ethiopia. PLoS ONE. 2010;5(10):e13268. doi:10.1371/journal.pone.0013268.

33. Guerreiro MF et al. Survival of adult AIDS patients in a reference Hospital of a metropolitan area in Brazil: Survival of patients with AIDS. Rev Saude Publica. 2001;36(3):278-84.

34. Deribew et al. Health and Quality of Life Outcomes. 2009;7:105 doi:10.1186/1477-7525-7-105.

Submit your next manuscript to BioMed Central and take full advantage of:

- Convenient online submission

- Thorough peer review

- No space constraints or color figure charges

- Immediate publication on acceptance

- Inclusion in PubMed, CAS, Scopus and Google Scholar

- Research which is freely available for redistribution 